\title{
Erratum: Self-encounters of the third kind: Iymph node stroma promotes tolerance to peripheral tissue antigens
}

\section{AY Collier, J-W Lee, and SJ Turley}

Mucosal Immunology (2008) 1, 248-251; doi:10.1038/mi.2008.19; published online 14 May 2008.

The second time reference no. 14 is cited in the text, (“...CD8 ${ }^{+}$T-cell tolerance to the melanocyte-associated antigen, tyrosinase. ${ }^{14 ”)}$ is incorrect. This section should instead cite an omitted reference:

Nichols, L.A., et al. Deletional self-tolerance to a melanocyte/melanoma antigen derived from tyrosinase is mediated by a radioresistant cell in peripheral and mesenteric lymph nodes. J Immunol. 179(2), p. 993-1003 (2007).

This reference is the same paper that is referred to again in the "New Directions" section on the third page in the first column as "The work of Nichols and colleagues", but there are no citation errors there other than the paper not being found in the references section. 